\title{
Award-winning papers in 2018
}

Papers published in Waste and Resource Management are eligible for awards from the Institution of Civil Engineers. Papers from any of the ICE journals can be nominated for several awards. In addition, each journal has awards dedicated to their specific subject area.

On Friday 4 October 2019, ICE president Andrew Wyllie presented awards to the following papers published in Waste and Resource Management in 2018. The editorial panel nominated their best papers and an awards committee chaired by Robert Armitage allocated the awards.

\section{Bill Curtin Medal}

The Bill Curtin Medal, awarded for the best paper on research innovation in civil engineering that leads to real-world impact, was awarded to Curry et al. (2018).

\begin{abstract}
Anaerobic digestion (AD) for biogas production forms one of the fundamental building blocks of the bioeconomy, and a research programme has been under way in Northern Ireland, which culminated in the publication of a Biogas Research Action Plan 2020 in 2014. One important element of this programme was the identification of the need for an evidence base for the potential bioresource feedstocks. This paper reports the outputs of the quantification of feedstocks for $A D$ research, which has identified the organic feedstocks available for biogas production on a regional basis and categorised these as: organic (biodegradable) fraction of municipal solid waste, sewage sludge, organic industrial and commercial wastes, manure from livestock, food wastes and energy crops. The research study further quantified the biogas and energy potential of these feedstocks and possible reductions in greenhouse gas emissions. The limitations of the research study are acknowledged and opportunities to address these and build on and extend the study are identified, including feedstocks for other bioeconomy processes and the application and further development of the biorefinery concept.
\end{abstract}

\section{Thomas Telford Premium Prize}

The Thomas Telford Premium Prize, presented for the best paper published in Waste and Resource Management, was awarded to Pérez-Camacho and Curry (2018).

\section{Abstract}

One of the outputs on an ongoing programme of research into the bioeconomy concept in Northern Ireland was the publication of a 'Biogas Research Action Plan' in 2014, which included a 'Quantification of Feedstocks for Anaerobic Digestion' research project. This research quantified the feedstocks available for biogas production on a regional basis. The present research builds on and extends that previous work by applying the anaerobic biorefinery concept to the data for feedstocks for anaerobic digestion to include both biogas and digestate utilisation options. The assessment aims at evaluating the potential significance of anaerobic biorefineries on a regional basis, including types of feedstocks and uses for both biogas and digestate outputs. The use of the anaerobic biorefinery concept allows the evaluation of both biogas and digestate management pathways in an integrated way and can contribute to the development of a road map for a regional bioeconomy. The usefulness of

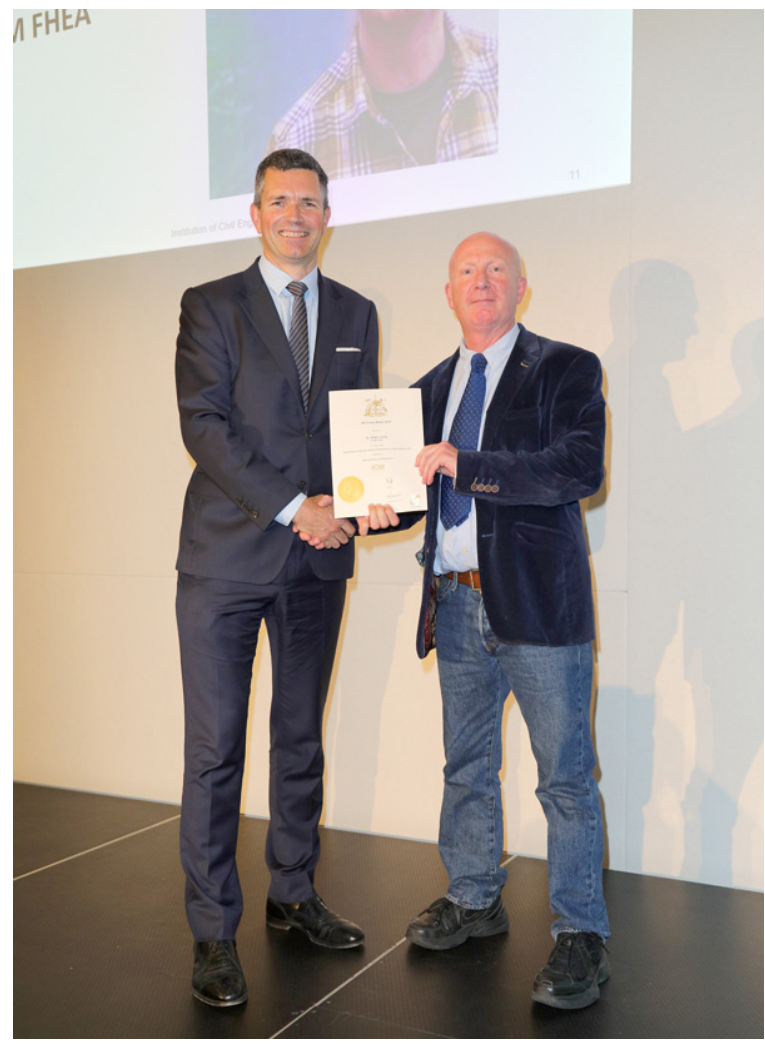

Robin Curry, winner of both the Bill Curtin Medal and the Thomas Telford Premium Prize, with ICE president Andrew Wyllie (left)

the anaerobic biorefinery concept in informing regional and/or national policy and decision-making for the circular economy and the bioeconomy is evaluated, and recommendations made for future research priorities in this important research and policy area.

\section{REFERENCE}

Curry R, Pérez-Camacho MN, Brennan R et al. (2018) Quantification of anaerobic digestion feedstocks for a regional bioeconomy. Proceedings of the Institution of Civil Engineers - Waste and Resource Management 171(4): 94-103, https://doi.org/10.1680/ jwarm.17.00014.

Pérez-Camacho MN and Curry R (2018) Regional assessment of bioeconomy options using the anaerobic biorefinery concept. Proceedings of the Institution of Civil Engineers - Waste and Resource Management 171(4): 104-113, https://doi.org/10.1680/ jwarm.17.00015. 